\title{
Study on Type Selection of Relays in Outdoor Terminal Box of Converter Station
}

\author{
Jianying WU ${ }^{1}$, Zhen WANG, Xilin YAN \\ Maintenance \& Test Center, CSG EHV Power Transmission Company, Guangzhou, \\ Guangdong Province,510663, China
}

\begin{abstract}
The outdoor terminal box of converter station's complex working characteristics and working environment easily leads to the failure of relays in it. The paper analyzes the key factors in relay selection from the perspectives of the characteristics of the operating environment. By comparing the characteristics of different component materials and structure designs, the paper proposes suggestions of type selection of relays in outdoor terminal boxes of converter stations.
\end{abstract}

Keywords. relays type selection, outdoor terminal box, component materials, structure design

\section{Introduction}

The outdoor terminal box of the converter station is vital in connecting and transferring between the primary equipment and the secondary equipment [1]. Secondary devices such as relays are usually placed in it. As the outdoor terminal box is directly exposed to the external environment without house protection, it is extremely easy to make the relays suffer from damages resulted from dust, moisture, temperature and other factors. When selecting the type of relays, the working environment, component material and structure designs should be considered. Consequently, the relays can be selected reasonably, used properly and related technical performance requirements could be met.

At present, there is scarcely any research on the type selection of relays in outdoor terminal box. The existing research largely analyzed the characteristics of relay failure and studied the measures. It describes the system principle of the relay and the selection of quality grade in the relay application and the principle of the relay derating use in reference [2]. Literature [3] analyzed the influence of ambient temperature, pressure and mechanical stress on the relay and proposed requirements for electrical parameters of relays. Literature [4] analyzed the electrical characteristics of the relays and put forward reliable use measures in coil connection, contact connection and arc suppression. Literature [5] proposed that the parallel contact structure can be used to improve the reliability of relay connection, and the series current-limiting resistance at the output of the contact can inhibit the impulse current.

The researches above make progress on analyzing the mechanism of relay failure, but there are unsolved issues as follows: 1) No comprehensive analysis of the operating

\footnotetext{
${ }^{1}$ Corresponding author: Jianying Wu, Maintenance \& Test Center, CSG EHV Power Transmission Company, No.223, Kexue Avenue, Huangpu District, Guangzhou, Guangdong Province, China; E-mail: wujaneyee92@163.com.
} 
environment stress of relays in outdoor terminal box. 2) No proposed approaches in relay type selection, owing to the complexity of the working environment.

That being said, this paper studies the operating environment characteristics of the outdoor terminal box and its influences on relays. Then the paper analyses the application conditions of different component materials and structure designs, and proposes the approach in type selection of relays to meet outdoor terminal boxes' environmental adaptability.

\section{Environmental Analysis of Relays in Outdoor Terminal Box}

\subsection{Analysis of Operation Environment}

The outdoor terminal box of converter station mainly includes CT, PT, circuit breaker, transformer control terminal box, etc. In most cases, the box is made of stainless steel with poor thermal insulation performance, fluctuating temperature and bad sealing [6]. In the DC converter stations, especially in Southern China, the terminal boxes are exposed to high temperature, damp air and dust, which are prone to lead to the potential safety concerns of the relays in the boxes, such as the deteriorated insulation performance, the components corrosion, the aging materials, and even the relay malfunction.

- $\quad$ Temperature and humidity

Converter stations were usually built in mountainous and humid areas, especially in Guangdong with an average air humidity above $77 \%$, due to the abundant rainfall. The temperature and humidity curves of an outdoor terminal box connected with a cable trench in Qiao Xiang Station are shown in Figure 1.

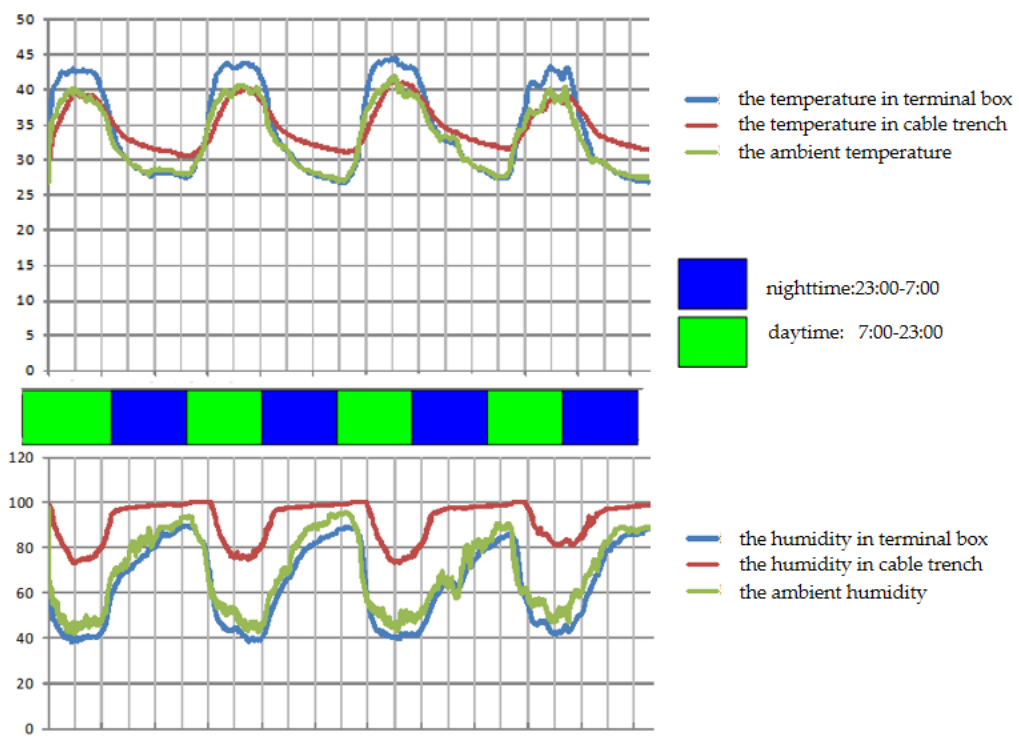

Figure 1. Temperature and Humidity Test Curve of Terminal Box in Qiao Xiang Station.

Test results of the temperature and humidity of the terminal box in the converter station showed that the relays mainly operate in the fluctuating high-temperature and 
high-humidity environment. The maximum temperature is over $40^{\circ} \mathrm{C}$ and the maximum humidity is over $95 \%$.

In rainy seasons, the humid air outside invades through terminal box doors, slots and fans. The secondary live equipment and heaters make the temperature inside the box higher. According to the relationship between saturated humidity of air and the temperature, if the relative humidity is high during the daytime, the moisture in the air saturates rapidly when the temperature drops at night [7]. As the shell of the terminal box dissipates heat faster, the air will condense at top of the terminal box or at the door with lower temperature.

A fan is installed in the terminal box to control internal temperature and draw out the moisture. Then the ventilation may carry external dust into the terminal box. There is also a risk of inlet external dust during open-box inspection and maintenance as Figure 2 shows.

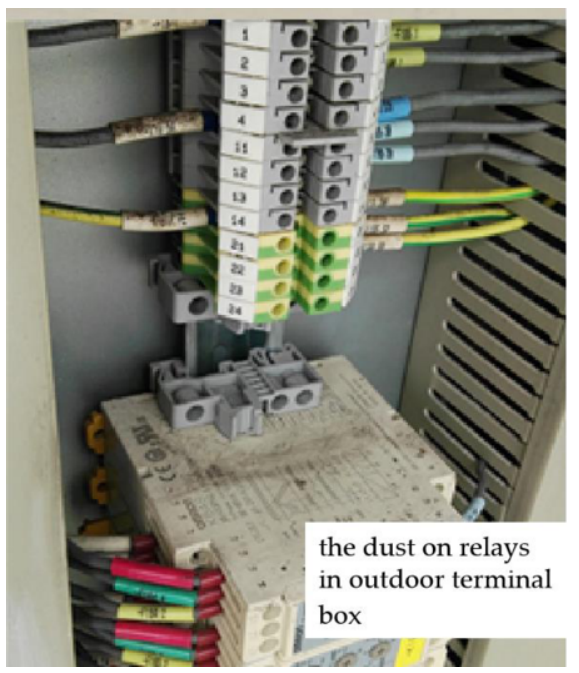

Figure 2. The dust accumulation on the surface of relays.

As it's easy to produce condensed water in the fluctuating high-temperature and high-humidity environment, the dust and the water mixed on the surface of the relays may lead to flashover or short-circuit.

\subsection{Influence of Environmental Parameters on Relays}

The national standard stipulates the requirements of standard limit values of the relays. The environmental temperature required in the national standard is $-25 \sim 40^{\circ} \mathrm{C}$, and the average temperature within 24 hours is below $35^{\circ} \mathrm{C}$. The monthly average maximum relative humidity of the wettest month should be lower than $90 \%$ with the monthly average minimum temperature of $25^{\circ} \mathrm{C}$, and there is no condensation on the surface. When the maximum temperature is $40^{\circ} \mathrm{C}$, the average maximum relative humidity should be under $50 \%$.

According to the environmental characteristics in outdoor terminal box, the ambient temperature and humidity in the terminal box of some converter stations may fail to meet the standard working conditions of relays. The main environmental parameters and impacts considered in the type selection of relays are shown in Table 1. 
Table 1. The main environmental factors and impacts.

\begin{tabular}{|c|c|c|}
\hline Environment & Appearance Failure Features & $\begin{array}{l}\text { Electrical Failure } \\
\text { Characteristic }\end{array}$ \\
\hline high temperature & $\begin{array}{l}\text { Softening and melting of } \\
\text { insulating materials }\end{array}$ & $\begin{array}{c}\text { The resistance of the coil and the } \\
\text { absorption voltage increase. } \\
\text { The arc breaking capacity is } \\
\text { reduced }\end{array}$ \\
\hline $\begin{array}{l}\text { fluctuating high and low } \\
\text { temperature }\end{array}$ & $\begin{array}{l}\text { Loose structure, change position } \\
\text { of moving parts }\end{array}$ & $\begin{array}{c}\text { Poor electrical connection of the } \\
\text { contact }\end{array}$ \\
\hline humid & $\begin{array}{c}\text { Electrochemical corrosion of } \\
\text { coils and other metal parts. } \\
\text { Plastic shell material aging } \\
\text { failure. }\end{array}$ & $\begin{array}{l}\text { The insulation performance } \\
\text { decreases and the arcing } \\
\text { phenomenon intensifies. }\end{array}$ \\
\hline dust deposition & $\begin{array}{l}\text { Dust deposits on the contact } \\
\text { surface to produce black oxide. }\end{array}$ & $\begin{array}{l}\text { The dust mix with condensation } \\
\text { may cause insulation failure. }\end{array}$ \\
\hline \multicolumn{3}{|c|}{$\begin{array}{l}\text { The main impacts of the environmental parameters on the relays in outdoor terminal } \\
\text { es are appearance and electrical failure characteristics. The appearance failure } \\
\text { acteristics are mainly shown in the metal corrosion of relays components, the aging } \\
\text { tic materials and the malfunction of contact materials. In the long term, appearance } \\
\text { Ire characteristics will develop into electrical failure such as insulation failures and } \\
\text { ounted electrical life. According to the environmental parameters and failure features, } \\
\text { type selection of relays can be standardized from the aspects of relay component } \\
\text { erials and structure designs. }\end{array}$} \\
\hline
\end{tabular}

\section{The Material of Main Components}

\subsection{The Shell Material of the Relays}

The shell material is vital for the basic protection of relays. The main components consist of plastic substrate and plastic additives. The main components of the rate substrate are made of thermoplastic materials, such as PBT, PET, PC, ABS and PS. The main components of plastic additives include phosphorus flame and bromine flame retardants.

Relay providers will adopt different materials depending on the users' scenario in most cases, and test on physical sustenance, safety features, temperature, and humidity. However, flame retardants with diversified ingredients and plastic substrate may lead to compatibility issues under exposure to high temperature and humidity, then the plastic additives gradually decomposed and precipitated to form oil conductive liquid [8]. The oil leakage and precipitated crystals on the plastic surface of the relays after long periods of operation, which led to risks including erosion of metal terminals, reduction in contact insulation and reliability. Unfortunately, mainstream relay manufacturers did not test on the exposure to the environmental conditions mentioned above.

$85^{\circ} \mathrm{C}$ and $85 \% \mathrm{RH}$ aging tests on the compatibility of various flame retardants and plastic substrate were conducted on the shell material components of typical relays' plastic shell. The results are shown in Table 2. 
Table 2. Compatibility tests $\left(85^{\circ} \mathrm{C}\right.$ and $85 \% \mathrm{RH}$ aging tests $)$.

\begin{tabular}{|c|c|c|c|}
\hline Plastic substrate & $\begin{array}{c}\text { Components of flame } \\
\text { retardants }\end{array}$ & Test results & Relay type \\
\hline $\mathrm{PBT}+\mathrm{PA}$ plastic alloy & $\begin{array}{l}\text { Phosphorus flame } \\
\text { retardants }\end{array}$ & $\begin{array}{l}\text { Leakage of conducted oil } \\
\text { liquid on relay's plastic } \\
\text { surface. }\end{array}$ & Siemens 7PA 2732 \\
\hline PS & $\begin{array}{l}\text { Small amounts of } \\
\text { bromine flame retardants } \\
\text { stuffed with glass fiber }\end{array}$ & $\begin{array}{c}\text { No compatibility issues } \\
\text { between additives and } \\
\text { substrate. }\end{array}$ & Siemens 7PA 2730 \\
\hline PET & $\begin{array}{l}\text { Small amounts of } \\
\text { bromine flame retardants } \\
\text { stuffed with glass fiber }\end{array}$ & $\begin{array}{l}\text { Organic crystals with } \\
\text { infinite resistance on } \\
\text { relay's plastic surface. }\end{array}$ & $\begin{array}{c}\text { Siemens 7PA2742, } \\
\text { Schneider REL91233 }\end{array}$ \\
\hline PBT & $\begin{array}{l}\text { Aluminum hydroxide } \\
\text { flame retardants stuffed } \\
\text { with glass fiber }\end{array}$ & $\begin{array}{c}\text { No compatibility issues } \\
\text { between additives and } \\
\text { substrate. }\end{array}$ & Finder 56.34.9.110.4000 \\
\hline
\end{tabular}

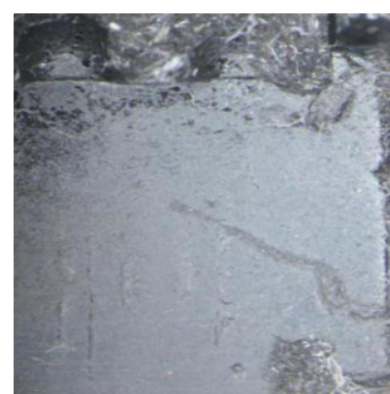

(a)

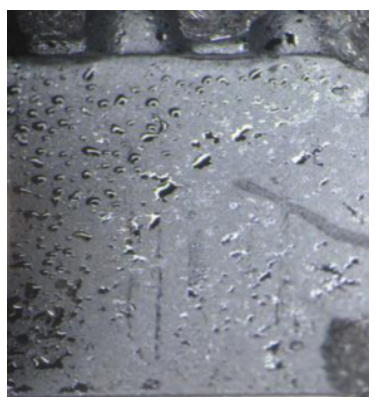

(b)

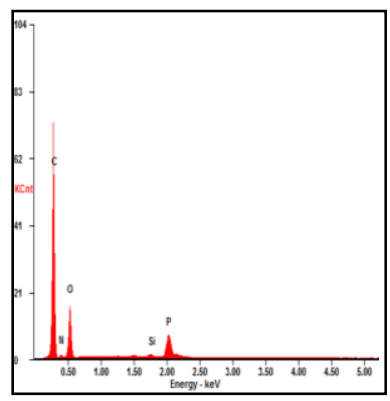

(c)

Figure 3. Changes of the plastic surface of sample relays before and after tests (Siemens 7PA2732) (a) Plastic surface of sample relays (pre-test) (b) Plastic surface of sample relays (post-test). (c)scanning electron microscope energy spectrum diagram of relay surface liquid.

Phosphorus flame retardants would leak, owing to easily decomposed features and poor compatibility with plastic substrates and other polymer materials [9]. The oil liquid precipitated in the test was detected by electron microscope energy spectrum analysis as Figure 3 shows. The results showed that the main elements of the oil liquid were carbon, oxygen, phosphorus and nitrogen. The oil liquid contained a large number of PO43through ion chromatography analysis. Tests showed that the oil liquid was conductive and was mainly decomposed from the phosphorus flame retardants. The leakage of oil liquid on the surface of relays made of phosphorus flame retardants and PBT+PA plastic substrate led to reduced shell insulation, increasing probabilities of electrochemical erosion on metal terminals, corrosion of terminals and even relay malfunction.

According to the experience and tests of retardants and substrates, relays with phosphorus flame retardants should be avoided considering the high temperature and humidity environments of outdoor terminal boxes. Manufacturers should be required to conduct $85^{\circ} \mathrm{C}$ and $85 \%$ RH aging tests on relays' plastic shell and provide related reports. Tests should proceed for more than 500 hours so that the reliability of relay's shell materials could be tested in exposure of high temperature and humidity.

\subsection{Metal Terminal Materials}

Terminals are mostly used as reliable physical and electrical connections among wires in relays. It consisted of conductive plates, screws and locator cards as Figure 4 shows. The analysis of the operational conditions of relays in terminal boxes showed that 
condensed vapor was likely to drop on the relays, leading to the erosion of terminals. So it's vital to select metal terminals materials to improve the corrosion resistance of terminals.

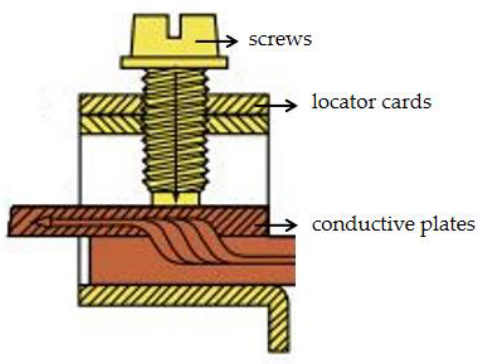

(a)

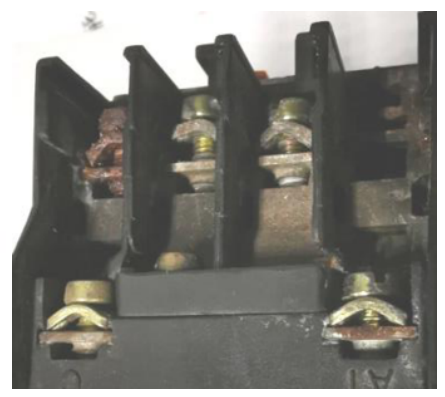

(b)

Figure 4. (a) structure of relay terminals (b) corrosion of relay terminals.

- Conductive plates

Conductive plates were supposed to maintain a permanent connection of airtightness and low resistance with wires. They are supposed to have excellent features of conductivity and resistance to erosion.

Copper and copper alloy were preferred connections in relay terminals, as such conductive plates. Copper has excellence in mechanical features, resistance to erosion and conductivity. In addition, same thermal expansion coefficient is shared between copper-made metal components and copper wires. As a result, loose connection caused by the discrepancy of thermal expansion under various temperatures could be avoided.

- Screws and locator cards

Screws and locator cards could firm the wires and were supposed to have excellent features of erosion resistance and adequate physical strength.

They were usually made of copper alloy or steel coated with stain-proof materials. Key material indicators were resistance to erosion and mechanical intensity. In principle, steel without stain-proof coating should not be used so that electrical erosion, unreliable electrical connection and rusted screws, caused by the battery effects between steel components and copper wires under wet conditions, could be avoided.

Relay OEMs usually electroplate the terminals in order to improve the wear resistance, conductivity, reflection and resistance to erosion. Coatings by major relay OEMs were mostly zinc, nickel and tin as Table 3 shows, owing to the trade-off between cost and effectiveness.

Table 3. Terminal materials of relays by mainstream OEMs.

\begin{tabular}{|c|c|c|c|c|c|}
\hline Metal components & & Tian Shui & Siemens 7PA & Weidmueller & Finder \\
\hline Screws & $\begin{array}{r}\text { Metal } \\
\text { substrates }\end{array}$ & Steel & Steel & Steel & Stainless steel \\
\hline & Coating & Zinc & Zinc & Zinc & Zinc \\
\hline Locator cards & $\begin{array}{c}\text { Metal } \\
\text { substrates }\end{array}$ & Steel & Steel & Steel & $\begin{array}{l}\text { Stainless steel } \\
\text { or copper alloy }\end{array}$ \\
\hline & Coating & Zinc & Zinc & Zinc & Zinc \\
\hline Conductive & $\begin{array}{r}\text { Metal } \\
\text { substrates }\end{array}$ & Steel & $\begin{array}{c}\text { Brass(Copper } \\
\text { alloy) }\end{array}$ & $\begin{array}{r}\text { Brass (Copper } \\
\text { alloy) }\end{array}$ & $\begin{array}{r}\text { Red copper } \\
\text { (Copper alloy) }\end{array}$ \\
\hline & Coating & Tian Shui & Tin & $\mathrm{Sn}-\mathrm{Pb}$ alloy & Nickel \\
\hline
\end{tabular}


Major features of the coating are as follows.

1)Zinc coating. Zinc coating is the anode for steel, which prevents the erosion of steel. Its effectiveness in protection and ornament is significantly enhanced after passivation and dyeing. Zinc coating is mostly used in screws and guide rails.

2)Nickel coating. Nickel is stable in the air, as the passivation will create a thin layer on the surface which protects the nickel from the erosion of air. Nickel coating is mostly used in screws, cube components and conductors.

3)Tin coating. Tin has good conductivity, welding and extension. It proves to be effective in erosion resistance but it's soft to be easily damaged. Tin coating is mostly used in pins.

According to the analysis above, suggestions on terminals material selection of relays are as follows.

1)Stainless steel and copper alloy were recommended to be used as materials for screws and locate cards, owing to their resistance to erosion.

2)Copper and its alloy were recommended as materials for conductive plates, owing to their conductivity.

3)Nickel coating and zinc coating with thick layers were recommended in relays, owing to their resistance to erosion and cost.

In additions, measures to improve the terminal boxes operating conditions were necessary to mitigate the erosion of relays' metal components.

\section{Relay Structure}

\subsection{Encapsulation Structure}

Encapsulation structures is one of the important factors affecting the reliability of relays. The common packaging methods of the relay are open, dustproof, plastic sealing and sealing.

In terms of protection characteristics, sealed relays (including sealed and plastic sealed relays) can isolate contacts and coils from the surrounding medium. This kind of relays can isolate the external environmental climate stress, but the structure and the analysis of the failure are complex. The non-sealed relays (including dust-proof and open relays) is highly sensitive to the environmental changes, and the long-term environmental pollution may lead to the decrease of the reliability of the relays. However, the structure is simple so the installation and maintenance are convenient.

In terms of electrical performance, the electrical durability of non-sealed relays is longer than sealed relays for loads above $2 \mathrm{~A}$. In practical applications, non-sealed relays are preferred if the environment permits.

The working current of the relays in the outdoor terminal box is usually between $2 \mathrm{~A}$ to $10 \mathrm{~A}$. So non-sealed relays are preferred considering the service life and the convenience of regular inspection and maintenance as the electrical wiring is very complex in the terminal box. According to the environmental characteristics in the outdoor terminal box, it is recommended to choose the dust proof cover relay or the open relay with the overall shell or environmental protection requirements. 


\subsection{The Structure of Auxiliary Contacts}

Due to the miniaturization of electrical control equipment, the structure of auxiliary contacts should be considered for the relays with multiple sets of auxiliary contacts. Poor structure design may lead to the short circuit in auxiliary contacts. The contact structure of some typical relays is shown in Figure 5.

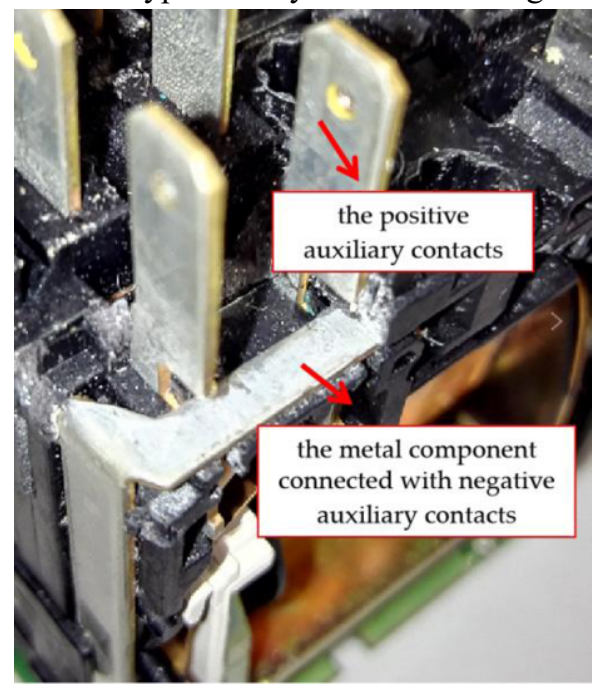

(a)

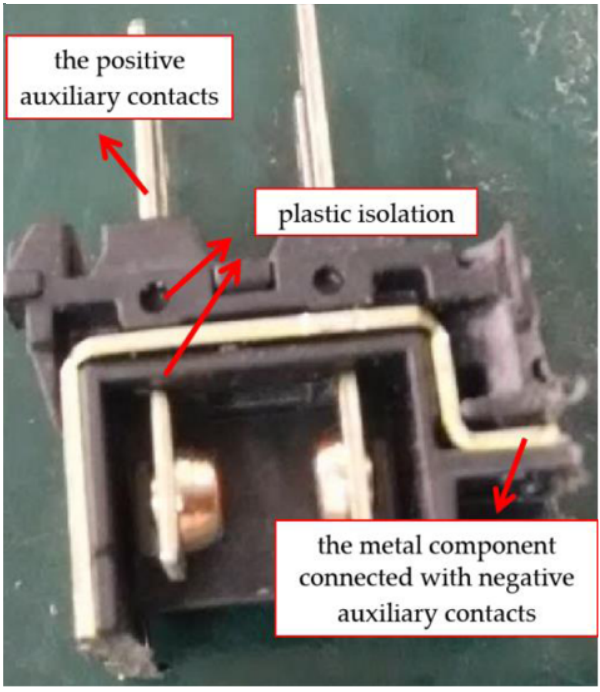

(b)

Figure 5. The structure of auxiliary contacts (a) the structure with no-plastic isolation (b) the structure with plastic isolation.

In figure (a), there is no plastic isolation between the positive auxiliary contact and the metal component connected with negative auxiliary contact. The distance between the two is around $1.8 \mathrm{~mm}$ with a hollow structure. In figure (b), there is plastic isolation between the positive auxiliary contact and the metal component connected with negative auxiliary contact.

As the conductive pollution may occur in outdoor terminal box, it is recommended to select the relays with plastic isolation between the positive and negative auxiliary contacts which can avoid insulation failure by pollutants.

\section{Conclusions}

The paper analyzes the working environment of the relays in the outdoor terminal boxes of the converter stations. The influences of environmental conditions such as fluctuating high and low temperature, humidity, dust, should be considered in the type selection of relays.

Through investigations and tests, the paper analyzes the typical materials and structures of relays and proposes several type selection tips, including phosphorus flame retardants should be avoided, stainless steel and copper alloy with coating were recommended to be used in terminals of relays, no-sealed relay with dust proof 
cover is preferred and it is recommended to select the relays with plastic isolation between the positive and negative auxiliary contacts.

\section{References}

[1] Zheng, X.X., Li, J.A., Song, S.B. Improvement and application of moisture-proof measures for outdoor terminal box in converter station. Electric Engineering, 2018; 15: 125-128.

[2] Zhou, Z.M., Li, Y., Analyzing selection and application of a relay. Electric Switchgear, 2004; (3).

[3] Li, D.X., Discussion on selection of electromagnetic relay and matters needing attention in use. Electromechanical Components, 2015; 02.

[4] Luo, L., Analysis of selection and reliable operation of electromagnetic relay. Automation and Instrumentation, 2014: 02.

[5] Lv, B., Wei, Y.M., Xiao, W.Z., Preliminary analysis of selection and reliable use of electromagnetic relay, Electronics World, 2021; 05:176-177.

[6] Feng, L., Wang, Z. Study on Outdoor Terminal box moisture-proof measures. Journal of Physics: Conference Series, 2019; Volume 1325.

[7] Xu, H, Yin, H.B., Liu, Q.Y., Solutions to the problem of condensation of substations in the south. Electrical Engineering, 2018; 19: 108-116

[8] Wang, Z., Yang, Y.F., Liu K., Relay insulation failure mechanism of Xing'an HVDC project and regulation measures. Guangdong Electrical Power, 2019; 32(08):126-132.

[9] Yan, H., Yang, J.F., Progress of phosphorus flame retardants' application in plastics. Plastics Additives 2015; (6):6-8. 